Archived version from NCDOCKS Institutional Repository http://libres.uncg.edu/ir/asu/

\title{
Appalachlyan
}

B O O N E, NORT H C A R O L I A

\section{Young adult romantic couples' conflict resolution and satisfaction varies with partner's Attention-Deficit/ Hyperactivity Disorder type}

\author{
Authors \\ Will H. Canu, Lindsey S. Tabor, Kurt D. Michael, Doris G. Bazzini, and Alexis L. Elmore
}

\begin{abstract}
Attention-deficit/hyperactivity disorder (ADHD) has previously been associated with less satisfaction and success in romantic relationships. This study compares conflict resolution and problem-solving behaviors in young adult romantic couples either having one partner with ADHD combined type (Ccouples), having one partner identified with ADHD inattentive type (IA-couples), or in which neither partner has an ADHD diagnosis (nondiagnosed [ND] couples). Self-reports of current and childhood ADHD symptoms corroborated diag-nostic status and speaker and listener behaviors, coded via the Rapid Couples Interaction Scoring System (Gottman, 1996), were the primary dependent variables. Analyses revealed greater negativity and less positivity in C-couples' behavior during a conflict resolution task, relative to IA and ND couples, and this corresponded with couples' relational satisfaction. IA-couples emitted relational behavior that was largely similar to ND couples. Findings support that relational impairment exists in C-couples, and to some degree, contrast with previous research suggesting that individuals with predominant inattention experience greater social impairment in adulthood than those with other types of ADHD.
\end{abstract}

Will H. Canu, Lindsey S. Tabor, Kurt D. Michael, Doris G. Bazzini, and Alexis L. Elmore (2013) " Young adult romantic couples' conflict resolution and satisfaction varies with partner's Attention-Deficit/Hyperactivity Disorder type" Journal of Marital and Family Therapy Version of Record Available @ (doi: 10.1111/jmft.12018) 


\title{
YOUNG ADULT ROMANTIC COUPLES' CONFLICT RESOLUTION AND SATISFACTION VARIES WITH PARTNER'S ATTENTION-DEFICIT/HYPERACTIVITY DISORDER TYPE
}

\author{
Will H. Canu, Lindsey S. Tabor, Kurt D. Michael, Doris G. Bazzini, and Alexis L. Elmore \\ Appalachian State University
}

Attention-deficit/hyperactivity disorder (ADHD) has previously been associated with less satisfaction and success in romantic relationships. This study compares conflict resolution and problem-solving behaviors in young adult romantic couples either having one partner with ADHD combined type (C-couples), having one partner identified with ADHD inattentive type (IA-couples), or in which neither partner has an ADHD diagnosis (nondiagnosed [ND] couples). Self-reports of current and childhood ADHD symptoms corroborated diagnostic status and speaker and listener behaviors, coded via the Rapid Couples Interaction Scoring System (Gottman, 1996), were the primary dependent variables. Analyses revealed greater negativity and less positivity in C-couples' behavior during a conflict resolution task, relative to IA and ND couples, and this corresponded with couples' relational satisfaction. IA-couples emitted relational behavior that was largely similar to ND couples. Findings support that relational impairment exists in C-couples, and to some degree, contrast with previous research suggesting that individuals with predominant inattention experience greater social impairment in adulthood than those with other types of ADHD.

Attention-deficit/hyperactivity disorder (ADHD) is one of the more prevalent psychological disorders in adulthood. Estimates put $2-10 \%$ of young adults as either meeting Diagnostic and Statistical Manual of Mental Disorders (fourth edition text revision, DSM-IV-TR; American Psychiatric Association, 2000) diagnostic criteria or experiencing substantial impairment due to persistent symptoms (Kessler et al., 2006; Weiss, Hechtman \& Weiss, 1999). ADHD combined type (ADHD-C), defined by clinically elevated inattentive and hyperactive-impulsive (HI) symptoms, accounts for the majority of cases, with the predominantly inattentive type (ADHD-IA) characterizing the bulk of the remainder (Wilens, Biederman \& Spencer, 2002). Impairment in adulthood manifests in lower educational and occupational status (Mannuzza, Klein, Bessler, Malloy \& LaPadula, 1993), negative self-image (Weiss et al., 1999), and social dysfunction, among other difficulties.

Interpersonal impairment related to ADHD is evident across development. Compared with nondiagnosed (ND) youth, those with ADHD are rated by peers and teachers as less socially competent and likeable (Gaub \& Carlson, 1997; Hoza et al., 2005) and experience negative interaction

Will H. Canu, PhD, is an Associate Professor in the Department of Psychology, Appalachian State University; Lindsey S. Tabor, MA, obtained her graduate degree clinical-health psychology at Appalachian State University, and currently works and resides in Columbia, South Carolina; Kurt D. Michael, PhD, is a Professor in the Department of Psychology, Appalachian State University; Doris G. Bazzini, PhD, is also a Professor in the Department of Psychology, Appalachian State University; Alexis L. Elmore, BS, obtained her bachelor's degree from the Department of Psychology, Appalachian State University, and currently is a doctoral student of clinical psychology at the University of Iowa.

Acknowledgments are due to Dr. Nicole Schatz for her contributions to the design and data collection effort in this research, to Dr. Brian Wymbs for his thoughtful comments on an earlier draft of this manuscript, and to the research assistants who assisted us in working with our participants. Of course, heartfelt thanks are extended to all of the couples who took part in this study; we wish them the best of luck and happiness in their relationships, current and future.

Address correspondence to Will H. Canu, Appalachian State University, Department of Psychology, 222 Joyce Lawrence Lane, Boone, NC 28608; E-mail: canuwh@appstate.edu 
patterns with teachers (Eisenberg \& Schneider, 2007), parents (Johnston \& Freeman, 1997), and peers (Mrug et al., 2009). Although these youths are aware of their maladaptive behaviors (e.g., interrupting, breaking rules, failing to attend to others), they typically lack the self-control to modify them (Hinshaw \& Melnick, 1995). Research on social outcomes in adults with ADHD has also documented greater difficulty in developing (Minde et al., 2003) and maintaining (Biederman et al., 2006) serious romantic relationships, as well as lower satisfaction within these relationships (Canu \& Carlson, 2007; Eakin et al., 2004). Behaviors that reflect impulsivity, inattention, and emotional lability in affected adults (e.g., says things without thinking, forgets conversations, trouble dealing with frustration) have all been noted to take their toll on the adjustment of couples (Robin \& Payson, 2002; review in Barkley, 2006).

Still, relatively few studies have focused on how adjustment in young adult relationships is related to ADHD status. What the existent literature does suggest is that impairment in romantic relationships appears to be ADHD type specific, with accelerated onset of sexual interactions, promiscuity, and unsafe sex noted in ADHD-C, while ADHD-IA correlates with a delay in these behaviors (Canu \& Carlson, 2003; Flory, Molina, Pelham, Gnagy \& Smith, 2006). Interactions between personality and ADHD may also affect relational adjustment; for instance, high rejection sensitivity (RS; misinterpreting, overreacting to social cues; Downey \& Feldman, 1996) has been positively associated with romantic success in college males with ADHD-C, converse to the trend in ADHD-IA and ND peers (Canu \& Carlson, 2007).

Whereas risky sexual behavior seems a relational hazard specific to the combined type, evidence suggests those with ADHD-IA may suffer a higher degree of rejection at early stages of adult romantic relationships. Canu and Carlson (2003) investigated in vivo, subtype-specific behaviors and other perceptions in the context of an interactive task with the opposite sex. Surprisingly, after a 1-min unscripted interaction in which they were blind to participants' ADHD status, female peer confederates reported more desire to continue the interaction and willingness to consider dating male undergraduates with ADHD-C, as compared to those with ADHD-IA. The confederates rated the latter as less assertive, and this same ADHD-IA group self-reported less interest in the task. Overall, the findings suggest that $\mathrm{HI}$ behaviors may receive initial positive appraisal by partners, while ADHD-IA behaviors are devalued (Canu \& Carlson, 2003). Other studies have found that strong negative feelings in a relationship with an ADHD partner tend to be attributed more so to behaviors corresponding with the inattentive ADHD symptoms than hyperactivity (Robin \& Payson, 2002). Indeed, inattention has been linked to time-sampled (Knouse et al., 2008) and selfreported (Norvilitis, Sun \& Zhang, 2010) social dysfunction in daily life, trends that did surface for hyperactivity-impulsivity. Taken together, this body of work suggests that the romantic behavior of those with ADHD-C includes greater assertiveness, earlier and more frequent sexual experiences (albeit with the associated risks), and contrasts with the passivity, disinterest, and inexperience of the ADHD-IA population.

\section{INTERACTIONAL PATTERNS, CONFLICT MANAGEMENT, AND ADHD}

Prior research regarding social development and ADHD notes deficits in behavioral self-regulation (e.g., unduly aggressive, disruptive responses in ADHD-C; Barkley, 2006; Hinshaw \& Melnick, 1995; Wymbs et al., 2012) and goal-oriented behavior (e.g., social passivity in ADHD-IA; Henker \& Whalen, 1999). Problematic self-regulation in turn negatively impacts planning and the ability to manage rapidly and substantially fluctuating emotions, especially in the context of an interpersonal exchange (Canu \& Carlson, 2007; Robin \& Payson, 2002; Weiss et al., 1999), all of which may hamper young adults with ADHD. More specifically, evidence suggests that verbal communication patterns of individuals with ADHD may also be dysfunctional, with spouses noting ill-considered statements and "zoning out" as particularly upsetting (Robin \& Payson, 2002). Importantly, the ability to effectively manage various aspects of dyadic interaction in romantic couples, regardless of psychiatric status, has been shown to be associated with short- and longterm success or failure (Gottman \& Driver, 2005; Gottman \& Levenson, 2000). For instance, Gottman and Levenson (2000) followed married couples more than 14 years and found that both those who evidenced "attack-defend" (e.g., criticism, defensiveness, contempt) or "withdrawing" (sadness, disgust, stonewalling) styles during a videotaped conflict discussion were more likely to 
divorce, with the former style associated with speedier dissolution (5 vs. 16 years postmarriage). In contrast, those who exhibited positive interaction during the discussion at the onset of the study were likely to remain intact. Some of the established relational impairments of both ADHD types (e.g., aggression, passivity) are hypothetically consistent with these interactional predictors of divorce (i.e., attack-defend and withdrawal, respectively). Further, given the forms of communication that have been shown to be most associated with success in romantic relationships (e.g., responsive conversation, effective conflict resolution; Gottman \& Driver, 2005; Schneewind \& Gerhard, 2002), core ADHD features like impulsivity and inattention seem likely to portend unfavorable relational outcomes.

\section{THE CURRENT STUDY}

Evidence suggests that adult romantic couples with ADHD partners are less satisfied in their relationships (Canu \& Carlson, 2007; Murphy \& Barkley, 1996) and that such dyads are characterized by dysfunctional conflict styles marked by low frustration tolerance, unresponsiveness, and heightened risk of physical and verbal abuse (Robin \& Payson, 2002; Wymbs et al., 2012). Similarly, dysfunctional relational patterns put romantic relationships at risk for dissolution, regardless of diagnosis (Gottman \& Driver, 2005; Gottman \& Levenson, 2000). However, no known published studies have examined important in vivo dyadic behaviors, such as conflict resolution, in relationships where at least one partner has been diagnosed with ADHD, a notable methodological void in examining how the prominent ADHD types are associated with dysfunctional dyadic behavior and relational dissatisfaction. In an effort to address this shortcoming in the literature and to integrate the findings from general marital and family research, this study observed and coded the behavior of young adult couples during a 15-min conflict resolution task using the Rapid Couples Interaction Scoring System (RCISS; Gottman, 1996), which categorizes verbal and nonverbal behaviors into speaker and listener codes that have negative or neutral-positive valences (Gottman, 1996).

Specifically, (a) a greater prevalence of negative behaviors, and (b) a corresponding dearth of positive ones, was expected in ADHD couples interactions, as compared to ND dyads. Presumably, this would stem from a negative conflict style and difficulty with emotional regulation in ADHD partners and, hence, ineffective and negative affect-laden communication. Further, given that prior research suggests impulsivity to be the ADHD trait that best predicts interpersonal aggression (Theriault \& Holmberg, 2001), it was expected that (c) interactions of couples with an ADHD-C partner (C-couples) would include more critical, complaining, and outwardly rejecting behaviors than interactions of control couples and those with an ADHD-IA partner (IA-couples). Further, it was anticipated that (d) IA-couples would be less actively engaged, relative to ADHD-C dyads, reflecting previously noted passivity (Canu \& Carlson, 2003) and (e) that ADHD couples would report less relational satisfaction than controls.

\section{METHOD}

\section{Participants}

Participants were 63 romantic dyads, primarily composed of undergraduate students and recruited at two mid-sized public universities in the Midwest (MW) and the Southeast (SE) via newspaper, poster, e-mail announcements, and referrals from student services offices (e.g., counseling center, office of disability services). Recruitment materials and outlets targeted the ADHD and non-ADHD populations independently, although descriptions and incentives (i.e., payment) were identical. Eleven additional couples completed study procedures but were excluded to maintain the relative homogeneity of age (both partners $>3 S D$ above sample $M ; n=1$ ) and sexual orientation (couple with homosexual orientation; $n=1$ ) for interpretive purposes and to maintain diagnostic integrity (prior ADHD diagnosis without supportive data, $n=5$; no report ADHD with strong evidence therefore, $n=4$ ). While not a selection criterion, the vast majority reported heterosexual orientation, with three individuals reporting a bisexual preference. Overall, $86.5 \%$ of included participants were Caucasian; ages ranged from 17 years 5 months to 33 years 11 months. ${ }^{1}$ No demographic or diagnostic differences were noted across university cohorts. 
Table 1

Descriptive and Dependent Relational Satisfaction Variables Data

\begin{tabular}{|c|c|c|c|c|c|c|}
\hline & ND participants $(n=29)$ & ND partners $(n=29)$ & IA-probands $(n=14)$ & IA-partners $(n=14)$ & C-probands $(n=20)$ & C-partners $(n=20)$ \\
\hline Mage & $22.69(4.1)$ & $21.34(2.0)$ & $21.13(2.7)$ & $21.16(3.0)$ & $20.9(3.0)$ & $20.51(3.1)$ \\
\hline Minority (n/grp.) & Asian-3;AfrAm-1 & AfrAm-2;Asian-1 & AfrAm-1; Other-1 & Hisp-1 & AfrAm-3; Hisp-1 & AfrAm-2; Hisp-1 \\
\hline Educ. & $3.17(1.3)$ & $3.45(1.4)$ & $2.5(1.5)$ & $3.29(1.6)$ & $2.65(1.5)$ & $2.55(1.6)$ \\
\hline Sex & $79.3 \% \mathrm{M}$ & $20.7 \% \mathrm{M}$ & $85.7 \% \mathrm{M}$ & $14.3 \% \mathrm{M}$ & $75 \% \mathrm{M}$ & $25 \% \mathrm{M}$ \\
\hline WURS & $14.45(11.7)^{\mathrm{a}}$ & $19.45(12.0)^{\mathrm{a}}$ & $32.50(16.5)^{b}$ & $18.29(11.5)^{\mathrm{a}}$ & $53.58(15.1)^{\mathrm{c}}$ & $23.05(20.2)^{\mathrm{a}}$ \\
\hline \multicolumn{7}{|l|}{ CAARS } \\
\hline IA & $51.45(10.6)^{\mathrm{a}}$ & $48.62(7.6)^{\mathrm{a}}$ & $72.21(13.0)^{\mathrm{b}}$ & $51.29(10.9)^{\mathrm{a}}$ & $73.75(11.8)^{\mathrm{b}}$ & $52.70(14.6)^{\mathrm{a}}$ \\
\hline $\mathrm{HI}$ & $46.59(10.8)^{\mathrm{a}}$ & $45.21(7.1)^{\mathrm{a}}$ & $52.07(12.1)^{\mathrm{a}}$ & $46.71(7.2)^{a}$ & $70.35(14.6)^{b}$ & $49.75(12.8)^{\mathrm{a}}$ \\
\hline \multicolumn{7}{|l|}{ CSS } \\
\hline IA & $6.7(4.8)^{\mathrm{a}}$ & $7.71(4.8)^{\mathrm{a}}$ & $15.57(5.2)^{\mathrm{b}}$ & $5.43(6.6)^{\mathrm{a}}$ & $17.73(6.1)^{\mathrm{b}}$ & $9.18(8.9)^{\mathrm{a}}$ \\
\hline $\mathrm{HI}$ & $6.6(3.4)^{\mathrm{a}}$ & $6.0(2.8)^{\mathrm{a}}$ & $8.71(3.6)^{\mathrm{a}}$ & $8.0(5.8)^{\mathrm{a}}$ & $19.91(6.2)^{b}$ & $8.73(7.2)^{\mathrm{a}}$ \\
\hline ODD & $5.43(4.2)^{\mathrm{a}}$ & $7.71(5.5)$ & $6.57(6.1)$ & $3.71(3.0)^{\mathrm{a}}$ & $11.73(4.4)^{\mathrm{b}}$ & $6.82(4.3)^{\mathrm{a}}$ \\
\hline $\mathrm{CD}$ & $2.43(2.7)$ & $1.14(1.8)$ & $1.14(1.3)$ & $1.00(1.7)$ & $1.91(1.8)$ & $1.1(1.3)$ \\
\hline \multicolumn{7}{|c|}{ Current psychological treatment } \\
\hline $\operatorname{Med}(\mathrm{s})$ & $0 \%$ & $0 \%$ & $29 \%$ & $0 \%$ & $40 \%$ & $5 \%$ \\
\hline Psych & $0 \%$ & $0 \%$ & $7 \%$ & $0 \%$ & $0 \%$ & $0 \%$ \\
\hline Both & $7 \%$ & $0 \%$ & $21 \%$ & $7 \%$ & $15 \%$ & $0 \%$ \\
\hline RAS* & $3.57(0.33)^{\mathrm{c}}$ & $3.48(0.48)^{\mathrm{c}}$ & $3.38(0.64)^{\mathrm{c}}$ & $3.25(0.78)^{\mathrm{bc}}$ & $2.79(0.80)^{\mathrm{a}}$ & $3.14(0.56)^{\mathrm{b}}$ \\
\hline
\end{tabular}

Note. ND = nondiagnosed, proband-matched; IA-, C-probands = attention-deficit/hyperactivity disorder (ADHD) predominantly inattentive or combined participants; IA-, Cpartners = probands' nondiagnosed romantic partners; age = years; AfrAm = African American; Hisp = Hispanic; Educ. = years of college completed; $\mathrm{M}=$ male (females remainder of 100\%); parenthetical values $=S D s$; WURS $=$ Wender Utah Rating Scale; CAARS-IA $=$ Conners Adult ADHD Rating Scale-inattentive $(t$ score); CAARS$\mathrm{HI}=$ Conners Adult ADHD Rating Scale-hyperactive/impulsive ( $t$ score); CSS = Childhood Symptom Scale raw scores; IA = inattentive symptoms (CSS-IA-Male $1.5 S D>$ mean = 20.1, Female = 17.1); HI = hyperactive/impulsive symptoms (CSS-HI-Male $1.5 S D>$ mean = 19.7, Female = 18.0); ODD = oppositional defiant disorder symptoms (1.5 SD > mean in sample = 15.01); CD = conduct disorder symptoms $(1.5 S D>$ mean in sample $=4.12)$. RAS $=$ Relationship [satisfaction] Assessment Scale. CSS used in second cohort, only; $n \mathrm{~s}$ : ND $n=7,-\mathrm{IA} n=7,-\mathrm{C} n=11$.

Superscripts indicate pairwise differences $(p<.05)$; alphabetical order conforms to low-to-high means; multiple superscripts = statistical similarity to multiple groups; no superscript $=n s$ differences 9 groups.

*Group and pairwise results from nonparametric Kruskal-Wallis and Mann-Whitney U-tests due to violation of homogeneity of variance assumption for ANOVA. 
Participants were not excluded due to the presence of other mental disorders: four with ADHD-IA and six with ADHD-C diagnoses self-reported a comorbid axis I disorder. Within these two subgroups, $57.0 \%$ and $55.0 \%$, respectively, reported currently undergoing treatment to address their ADHD, far exceeding the rate in other groups (see Table 1 for details). Participants using medication to address ADHD symptoms were asked to abstain the day of the study (IA proband $^{2}$ compliance $=86 \%, C=60 \%$ ). Reports regarding who provided the historical ADHD diagnoses were as follows: psychiatrist $=41.2 \%$, psychologist $=17.6 \%$, general practice $\mathrm{MD}=23.5 \%$, counselor $=5.9 \%$, other mental health practitioner $=5.9 \%$ (no response $=5.9 \%$ ). The final groups from each cohort were as follows: C-couples (MW $n=9$; SE $n=11$; Age $M=20.7$ years), IA-couples (both $n=7$; Age $M=21.2$ ), ND couples (MW $n=22$; SE $n=7$; Age $M=22.0$ ). Tables 1 and 3 further detail participant characteristics (see also Other measures, below).

\section{Measures}

Conners' Adult ADHD Rating Scale: Screening Version (CAARS). The CAARS (Conners, Erhardt \& Sparrow, 1999) is a 30-item, short-form measure tapping DSM-IV-TR ADHD symptoms. Responses follow a 4 -point Likert format $(0=$ not at all or never, $3=$ very much, very frequently); two, nine-item scales corresponding to the inattentive (e.g., I have trouble keeping my attention focused when working) and HI (e.g., I am always on the go) symptom clusters are utilized herein. Internal consistency for both was excellent ( $a=.91, .86$, respectively). Test-retest reliability and clinical utility have also been proven robust; the long-form of this measure, from which the version utilized herein was derived, has been shown to accurately classify ADHD at a rate of $85 \%$ (Conners et al., 1999), suggesting satisfactory discriminant validity.

Childhood Symptom Self-Report Scale (CSS). This scale by Barkley and Murphy (2006) is a retrospective self-report of ADHD symptoms from age 5 to 12 . The scale has a 4-point Likert format $(0=$ never or rarely, $3=$ very often). Inattentive and HI subscales (nine items each, tapping DSM-IV-TR criteria) showed satisfactory internal reliability here ( $a=.93, .91$, respectively) and elsewhere ( $M a=.76$; Fedele, Hartung, Canu \& Wilkowski, 2010). An example item from the inattentive scale is Didn't listen when spoken to directly, and another representing hyperactivity-impulsivity is Had difficulty awaiting turn. The CSS adequately distinguishes ADHD from ND and clinical control cases and correlates well with parent reports $(r=.73$; Barkley, Knouse \& Murphy, 2011).

Wender Utah Rating Scale (WURS; Ward, Wender \& Reimherr, 1993). This retrospective self-report form has 25 items that discriminate ADHD and ND samples. Items follow a 5-point format ( 0 = not at all or very slightly, $4=$ very much); a sum score of 36 or higher produces $96 \%$ sensitivity and specificity for ADHD. Internal consistency was robust $(a=.94)$, and split-half reliability has been shown to be similarly strong ( $r=.9$; Ward et al., 1993). Associations with Conners' Parent Rating Scale ( $r s=.41-.49$ ) suggests convergent validity (Ward et al., 1993). Three-item inattention (IA) and HI subscales were constructed to evaluate childhood symptoms of the MW cohort. Example items for IA include concentration problems and trouble with stick-toitiveness, not following through, failing to finish things started; HI exemplars are acting without thinking and impulsive, losing control of myself. Analysis within this sample showed correlations across subscale items are robust (WURS-IA: $r(124)>.5, p<.001$; WURS-HI: $r(124)>.45$, $p<.001)$, as are internal consistency ( $a=.82$ and .77, respectively) and correlations with the CSS (WURS/CSS-IA $r=.72$; WURS/CSS-HI $r=.72$ ) in the southeast cohort. ND and ADHD groups in the MW cohort widely differed on these ad hoc subscales (WURS-IA: ND $M=2.1$ $[S D=2.1]$, both ADHD groups, 7.5 [3.1]; WURS-HI: ND 1.4 [1.53], participants with ADHD-C $4.95[2.95])$.

Rapid Couples Interaction Scoring System. The RCISS (Gottman, 1996) describes couples interactions via behavioral codes for both speaker and listener in conversational turns. Codes may be negative (e.g., Defensive) or neutral/positive (e.g., Humor). Combinations of codes sharing core behavioral concepts but occurring infrequently (0-10 occurrences per dyadic interaction) were created to enhance reliability (see Table 2 for descriptions). Proportional data are reported to control differences in verbosity (i.e., if "Defensive" is coded 10 of 100 total codes for the couples interaction, the score $=0.10$ ). Buehlman, Gottman and Katz (1992) reported inter-rater reliabilities for 


\begin{tabular}{|c|c|}
\hline RCISS code(s) & Description \\
\hline \multicolumn{2}{|l|}{ Negative codes } \\
\hline $\begin{array}{l}\text { Negative problem } \\
\text { talk/Complain }{ }^{\mathrm{a}}\end{array}$ & Verbal/affective negativity; notingproblem; whining \\
\hline Criticize/Putdown ${ }^{\mathrm{a}}$ & Verbal aggression; to blame, demean, embarrass \\
\hline "Yes, but"a & Qualified apology or agreement \\
\hline Defensive $^{\mathrm{a}}$ & Rejecting responsibility (e.g., "not me, it’s you") \\
\hline $\begin{array}{l}\text { Escalate negative } \\
\text { affect/Other negative } \mathrm{e}^{\mathrm{a}}\end{array}$ & $\begin{array}{l}\text { Obvious increase in negative affect; statement with } \\
\text { negative affect not otherwise coded. }\end{array}$ \\
\hline $\begin{array}{l}\text { Negative facial } \\
\text { expression }^{\mathrm{b}}\end{array}$ & Negative, inappropriate listener expression \\
\hline $\begin{array}{l}\text { Absence of } \\
\text { backchannels/ } \\
\text { Facial } \\
\text { movement }^{\mathrm{b}}\end{array}$ & $\begin{array}{l}\text { Disengagement in body language and expression; } \\
\text { (e.g., leaning away); static facial expression }\end{array}$ \\
\hline \multicolumn{2}{|l|}{ Positive codes } \\
\hline $\begin{array}{l}\text { Positive or neutral } \\
\text { problem talk/Assent }{ }^{\mathrm{a}}\end{array}$ & $\begin{array}{l}\text { Problem discussion with positive/neutral affect; } \\
\text { short assents (e.g., "uh-huh", "ok") showing involvement }\end{array}$ \\
\hline Task-oriented talk ${ }^{\mathrm{a}}$ & Statements reactions in the past, present, or future \\
\hline Humor/Other positive ${ }^{a}$ & Positive verbalization, including jokes, laughing \\
\hline $\begin{array}{l}\text { Positive facial } \\
\text { expression }^{\mathrm{b}}\end{array}$ & Positive expression while the speaker is talking \\
\hline Engagement code $^{\mathrm{b}}$ & $\begin{array}{l}\text { Engaged listening via body language (backchannels), } \\
\text { expression (facial movement) }\end{array}$ \\
\hline
\end{tabular}

Note. ${ }^{\mathrm{a}}$ Speaker codes. ${ }^{\mathrm{b}}$ Listener codes.

RCISS behaviors averaging 0.76 , and the measure has been shown to discriminate "regulated" from "unregulated" couples, the latter being more prone to low satisfaction and eventual separation (Gottman \& Levenson, 1992). Inter-rater agreement, determined using a random sample of approximately $20 \%(n=12)$ of dyads, was satisfactory $(79.1 \%$ agreement within and across all conversational turns).

Relationship Assessment Scale (RAS). The widely used RAS (Hendrick, 1988) has seven items with a 5-point, Likert-type format that measure perception of relationship qualities and partner behaviors (e.g., How well does your partner meet your needs?). Scores are item means and equate to level of satisfaction. Internal reliability in this $(a=.85)$ and other samples $(a=86)$ is robust, and the RAS has been shown to prospectively differentiate romantic couples that separate or remain intact ( $86 \%$ and $91 \%$ accuracy, respectively; Hendrick, 1988).

Other measures. In addition to demographic questions, a one-item measure was included to gauge commitment to the relationship. Responses were made on a 7-point scale $(0=$ just hanging out, 1 = starting to date, $2=$ dating, $3=$ seriously dating, $4=$ considering getting married, $5=$ have gotten engaged, $6=$ married). Agreement between partners was acceptable (unweighted $\mathbf{K}=$ .59 ), and this measure correlated substantially (Spearman's $p=.74$ ) but not perfectly with length of relationship, suggesting these are at least partly independent constructs. Responses in this sample were distributed as follows: starting to date, 3.2\%; dating, 9.5\%; seriously dating, $32.5 \%$; consider- ing marriage; $30.4 \%$; engaged, $11.5 \%$; married, $12.7 \%$. 


\section{Assignment to Groups}

Assignment of positive ADHD status required (a) a report of a previous formal diagnosis with (b) corroborating data regarding current symptoms and impairment from study measures, (c) significant impairment endorsed during childhood ( ::; age 12), and (d) expert group consensus. More specifically, participants were designated ND in the absence of any reported childhood ADHD symptoms above the clinical threshold (2:1.5 $S D$ above mean). Participants were included in an ADHD group if a formal diagnosis was reported and at least two indicators were above clinical cutoffs. As the diagnosis of ADHD has been described as a "clinical decision-making process" (Rosler et al., 2006, p. 12), requiring consideration of multiple measures, the first, second, and third authors - the first and third practicing licensed psychologists with extensive child clinical training-synthesized the data from the Conners', Wender, and Childhood Symptom scales to make consensus decisions about inclusion and group membership for each case. History of pharmacological and other treatment was examined to ensure consistency with group membership. ADHD type was determined as follows. Predominantly inattentive (i.e., ADHD-IA) status was assigned if the Conners' inattention scale $t$ score 2: 65 (i.e., >93rd \%ile), with no corresponding elevation for hyperactivity-impulsivity. The combined type (i.e., ADHD-C) designation was made for similarly elevated scores on (a) Conners' inattention and (b) Conners', Wender, or Childhood Symptom hyperactivity-impulsivity scale. Further detail regarding diagnostic data is noted below and in Table 1.

\section{Procedure}

After informed consent, participants independently completed the Relationship Problem Inventory (RPI; Melby, Ge, Conger \& Warner, 1995), which taps areas of disagreement for couples and was used to identify topics for the conflict resolution task. Subsequently, participants completed a demographic survey, Conners', Wender, Childhood Symptom (SE cohort only), Relational Assessment, and several other scales (not detailed herein). Couples completed the questionnaires in order, without talking, and an experimenter was available to privately answer questions. After both partners finished, the couple was reunited and given four discussion topic cards. Three topics were generated from their RPI responses and presented in descending order of contentiousness, from mutually agreed upon "most difficult" to third most difficult; the final card asked the couple to continue discussion on other topics about which they have disagreement. Couples were asked to interact with the purpose of agreeing on solutions to these relational issues. The experimenter started recording with a video camera in plain sight and exited the room. Fifteen minutes later, the experimenter ended the interaction. Participants were debriefed, paid (\$10.00), and given referral information for local psychological services. The Institutional Review Boards of the respective universities approved all procedures.

\section{Data Analytic Strategy}

Analysis of variance (ANOVA and MANOVA, as appropriate) and chi-square analyses were employed to examine group differences on demographic and dependent variables, as indicated by type of data. Follow-up two-tailed $t$ tests were employed, as needed. Where the homogeneity of variance assumption for parametric ANOVA tests was not met, Kruskal-Wallis (yielding $\mathrm{v}^{2}$ ) and Mann-Whitney analyses (yielding $U$ ), which are nonparametric and thereby robust even with heterogeneous variance across groups, were used in lieu of $F$ and $t$ tests, respectively. Effect sizes were calculated to better describe differences.

\section{RESULTS}

\section{Preliminary Analyses}

No group differences in age or education were detected by ANOVA [age: $F(5,120)=1.49$, $n s$; education level: $F(5,120)=1.68, n s]$ or chi-square tests [ethnicity: $\mathrm{v}^{2}(20, N=126)=22.78, n s$ ]. Therefore, demographic variables were not controlled for, subsequently. ${ }^{3}$ MANOVA was used to examine differences between groups on current (Conners' scales) and childhood ADHD symptoms (CSS and Wender scales). There was a significant omnibus effect, $\Lambda=.218, F(5,44)=2.44$, $p<.001$, all follow-up ANOVAs were significant (Wender $p=.007$; Conners' and CSS inattention 
and hyperactivity-impulsivity scales all, $p<.001$, all $d f=5$, 44), and pairwise two-tailed $t$ tests all showed thesedifferences werein expected directions (see Table 1).

Composite RCISS variables were created to index overall positive, negative, and engagement behaviors exhibited in the conflict resolution task. The negative behavior composite is calculated by summing all negative codes and dividing by the total number of codes in each couple interaction, providing a relative index of negativity. The positive composite is formulated in like fashion utilizing positive and neutral RCISS codes, with the engagement composite calculated using facial movement and backchannels behaviors (see Table 2 for descriptions).

\section{Hypothesis One: Negative Conflict Behaviors}

Kruskal-Wallis and follow-up Mann-Whitney analyses revealed couples with an ADHD-C partner (C-couples) to emit more negative behaviors than other couples (see Tables 3 and 4 for

Table 3

Dependent Rapid Couples Interaction Scoring System (RCISS) and Other Couple-level Data

\begin{tabular}{|c|c|c|c|c|}
\hline & $\begin{array}{l}\text { ND couples } \\
(n=29)\end{array}$ & $\begin{array}{l}\text { IA-couples } \\
(n=14)\end{array}$ & $\begin{array}{l}\text { C-couples } \\
(n=20)\end{array}$ & Differences \\
\hline \multicolumn{5}{|c|}{ RCISS negative variables } \\
\hline RCISSneg & $4.03(4.6)^{\mathrm{a}}$ & $7.77(11.8)^{\mathrm{a}}$ & $11.12(8.5)^{b}$ & $\begin{aligned} \mathrm{v}^{2} & =13.22, \\
p & =.001\end{aligned}$ \\
\hline Defensive & $0.16(0.3)^{\mathrm{a}}$ & $0.64(0.9)^{b}$ & $0.79(0.9)^{\mathrm{b}}$ & $\begin{aligned} v^{2} & =13.52, \\
p & =.001\end{aligned}$ \\
\hline $\begin{array}{l}\text { Neg. problem talk/ } \\
\text { Complain }\end{array}$ & $0.97(1.9)^{\mathrm{a}}$ & $2.77(5.9)$ & $4.03(4.2)^{\mathrm{b}}$ & $\begin{aligned} \mathrm{v}^{2} & =10.87 \\
p & =.004\end{aligned}$ \\
\hline Criticize/Put down & $0.16(0.4)^{\mathrm{a}}$ & $0.81(1.8)^{\mathrm{a}}$ & $0.83(0.9)^{b}$ & $\begin{array}{c}\mathrm{v}^{2}=16.13, \\
p<.001\end{array}$ \\
\hline "Yes, but" & $1.31(1.1)^{\mathrm{a}}$ & $1.06(0.9)^{\mathrm{a}}$ & $2.09(1.5)^{b}$ & $\begin{array}{l}F=3.84 \\
p=.027\end{array}$ \\
\hline RCISSpos & $41.91(4.2)^{\mathrm{a}}$ & $39.15(9.3)$ & $36.14(1.7)^{b}$ & $\begin{array}{c}\mathrm{v}^{2}=8.96 \\
p=.011\end{array}$ \\
\hline RCISS engagement & $53.07(15.5)^{\mathrm{a}}$ & $58.53(12.2)^{\mathrm{a}}$ & $66.02(11.7)^{\mathrm{b}}$ & $\begin{aligned} \mathrm{v}^{2} & =9.38 \\
p & =.009\end{aligned}$ \\
\hline Length (months) & $24.47(17.1)$ & $21.61(18.8)$ & $18.14(17.6)$ & $\begin{array}{l}F=0.77 \\
p=.47\end{array}$ \\
\hline Seriousness & $4.06(1.1)^{b}$ & $3.86(1.29)^{b}$ & $3.25(1.2)^{\mathrm{a}}$ & $\begin{aligned} F & =2.85 \\
p & =.066\end{aligned}$ \\
\hline
\end{tabular}

Note. ADHD = Attention-Deficit/Hyperactivity Disorder; ND = nondiagnosed; IA = Inattentive Type; $\mathrm{C}=$ combined type; $d f$ for $F$ tests $=(2,59)$, for $v^{2}=(2, N=62)$. All $v^{2}$ statistics result from nonparametric Kruskal-Wallis tests, used when ANOVA homogeneity of variance assumptions was violated; pairwise comparisons with these were used nonparametric Mann-Whitney U-tests. Seriousness $=$ of relationship, $0=$ just "hanging out", $6=$ married . RCISS $=$ Rapid Couples Interaction Scoring System; RCISSneg = composite negative score; RCISSpos $=$ composite positive score. RCISS scores $=\%$ of total codes/couple interaction; $\%$ s do not total $100 \%$ because some irrelevant codes are omitted. Engagement $\%=$ ratio of turns containing that code out of the total turns per interaction (not a true percentage of the totalbehaviors).

Superscripts indicate pairwise differences of $p<.05$; alphabetical order conforms to low-tohigh means; groups with no superscript did not statistically differ from other groups. 
Table 4

Magnitude of Select Group Differences (Cohen's d)

\begin{tabular}{|lccc|}
\hline & IA vs. C & ND vs. C & ND vs. IA \\
\hline RCISSneg. & -0.34 & -1.14 & -0.54 \\
Defensive & -0.16 & -1.12 & -0.90 \\
Criticize/Put Down & -0.04 & -1.12 & -0.77 \\
Negative Talk/Complain & -0.25 & -1.07 & -0.56 \\
"Yes, but" & -0.85 & -0.63 & 0.24 \\
RCISSpos & 0.38 & 1.06 & 0.47 \\
RCISS engagement & -0.63 & -0.93 & -0.38 \\
Satisfaction(RAS) & 0.53 & 1.19 & 0.47 \\
\hline Note. Negative $d s$ indicate lower means in the first group; positive values indicate the \\
converse. |Effect size| $>$ 0.20 = small, > 0.50 = medium, > 0.80 = large. ADHD = Atten- \\
tion-Deficit/Hyperactivity Disorder. Couple groups: IA = with inattentive type partner; \\
C = with combined type partner; ND = no ADHD partner. RCISSneg = composite nega- \\
tive score; RCISSpos = composite positive score. RAS = Relationship Assessment Scale. \\
\hline \multicolumn{4}{l}{} \\
\hline
\end{tabular}

details); this result also indicated that analysis of differences across individual RCISS negative codes associated with the third hypothesis was warranted. Couples with an ADHD-IA partner (IA-couples), however, did not emit statistically more negative behavior than their ND peers. As such, this hypothesis was partly supported.

\section{Hypothesis Two: Positive Conflict Behaviors}

A Kruskal-Wallis test signaled group differences on the positive composite. Pairwise MannWhitney analyses showed that C-couples exhibited fewer positive behaviors than ND couples (see Tables 3 and 4). However, as IA-couples did not differ from their ND counterparts, the hypothesis was only partly supported.

\section{Hypothesis Three: Criticism, Complaint, and Rejection}

Four behaviors (Defensive, Criticize/Put Down, Negative Talk/Complain, and "Yes, but," see Table 2) corresponding to those Gottman (1996) found most predictive of relational dissolution were examined. Analyses (ANOVA and $t$ tests used for "Yes, but," Kruskal-Wallis with Mann- Whitney U-tests for others) indicated group differences across all variables, with C-couples generally emitting these significantly more than both IA- and ND couples, and IA- and ND couples not differing (see Tables 3 and 4). However, both IA- and C-couples used Defensive utterances more than ND couples. Overall, the hypothesis that C-couples would engage in these particularly relationally damaging behaviors more than others was supported.

\section{Hypothesis Four: Engagement Behaviors}

Kruskal-Wallis and Mann-Whitney analyses of the engagement composite indicated that nonverbal engagement also varied across couple groups. IA-couples evinced less of this type of behavior than C-couples, supporting the hypothesis (see Table 3). IA-couples, however, were statistically equivalent to their ND peers (see Table 3).

\section{Hypothesis Five: Relational Satisfaction}

Differences were noted across couple groups on relational satisfaction (i.e., RAS score) generally conforming to the trend for C-couples to engage in more negative conflict behavior, Kruskal- Wallis $\mathrm{v}^{2}(2, N=62)=11.57, p=.003$, and partly supporting the hypothesis. Follow-up Mann- Whitney U-tests showed dyadic satisfaction for C-couples to be significantly below that of 
IA-couples and even further below that of ND couples (ND $M[S D]=3.52(0.3)$, IA = 3.32 [0.69], $C=2.69$ [0.69]; see Table 4). More specifically, at theindividual participantlevel (Kruskal-Wallis $\left.\mathrm{v}^{2}[5, N=126]=18.01, p=.003\right)$, both ND subgroups reported more satisfaction than participants with ADHD-C and their partners, and participants with ADHD-IA were more satisfied than their counterparts with ADHD-C (all Mann-Whitney U-tests <.02; See Table 1). Despite these group differences, post hoc ANOVAs showed length of relationship and nominated seriousness (i.e., commitmentrating) did notvary across couple groups (seeTable 3). Finally, it is also notable that post hoc correlational analyses showed relational satisfaction to be negatively related to the negative composite RCISS variable, $r(62)=-.48, p<.001$, and that the inverse relationship was noted with the positive composite, $r(62)=.51, p<.001$.

\section{DISCUSSION}

This study investigated the differences in conflict resolution behavior and satisfaction in longterm, young adult, heterosexual couples with and without a partner diagnosed with predominantly inattentive or combined type ADHD, focusing on a systematic observation of dyadic interactions. Overall, couples with an ADHD-C partner (C-couples) exhibited more negative conflict resolution and less satisfaction than couples with an ADHD-IA partner (IA-couples) and ND dyads. Detailed discussion follows.

\section{In vivo Conflict Resolution Behaviors}

Results from the conflict resolution task support a priori hypotheses and suggest that the presence of a partner with ADHD is associated with maladaptive dyadic conflict resolution (i.e., more negative behavior, less positive), but this finding is essentially limited to C-couples. Given the realtime, speaker-listener coding scheme of the RCISS, this effectively means C-couples simultaneously exhibited more negative behaviors and fewer positive behaviors: a virtual "double whammy" for its potential impact on relational satisfaction, given the RCISS-RAS associations noted above. Equally compelling, perhaps, is that all the negative behaviors identified by Gottman (1996) as discriminants of relationships headed for dissolution-his "Four Horsemen of the Apocalypse" (i.e., complaints, criticisms, put-downs, and defensiveness, including "Yes, but" statements)—were significantly more common in C-couples, as compared to ND dyads, and all but one (i.e., defensiveness) in comparison with IA-couples. This pattern fits the "attack-defend" style predicting divorce among couples followed longitudinally (Gottman \& Levenson, 2000). If these toxic behaviors extend beyond conflict resolution within a given relationship to more mundane, daily interactions, they may help account for increased rates of divorce in those with ADHD-C (Gottman \& Driver, 2005; Murphy \& Barkley, 1996).

In contrast, IA-couples exhibited minimal negativity as compared to the ND dyads, in the form of defensiveness. What specific to combined type ADHD (ADHD-C) could explain the adequate performance of IA-couples? As noted, the disruptiveness and competitiveness of children with ADHD-C, generally not exhibited by those with Predominantly Inattentive ADHD (ADHDIA), engender dislike by peers (Carlson, Booth, Shin \& Canu, 2002; Gaub \& Carlson, 1997; Graetz et al., 2001; Hinshaw \& Melnick, 1995). Persistent intrusiveness in young adulthood may be reflected by the higher rates of criticism and put-downs in ADHD-C couples, and competitiveness could relate to elevated defensiveness. Characteristics associated with ADHD-IA in child (Gaub \&

Carlson, 1997) and college populations (Canu \& Carlson, 2003), such as passivity, may hinder romantic relationship initiation, but they also may be less likely to emerge as active negativity in a verbal interaction and may consequently cause less relational disruption.

Alternatively, the interpersonal behaviors of those with ADHD-C may be influenced by positive illusory bias - an inflated sense of personal competence, well documented in children with ADHD-C (Evangelista, Owens, Golden \& Pelham, 2008). If such a bias continues in affected adults (see Canu \& Carlson, 2007; Knouse, Bagwell, Barkley \& Murphy, 2005), this may hinder detection of a partner's cues, deterring conflict resolution and potentially escalating negativity. Further, research in children with ADHD has noted their difficulty fitting social behavior to context (Hinshaw \& Melnick, 1995), which could be manifested by a failure to self-monitor in a negatively toned conversation. Future research might examine this issue via analysis of transitional 
probabilities between conversational behaviors in conflict resolution of couples with ADHD or employ longitudinal data in an actor-partner interdependence model analysis. Finally, while it was expected that the IA-couples would exhibit low conversational engagement, this was confirmed only relative to $\mathrm{C}$-couples. Unfortunately, because C-couples frequently utilized negative statements and facial expressions, listener engagement likely involved negative nonverbal communication, worsening the tone of the conversation. Thus, the nonverbal responsiveness of these couples may have inhibited conflict neutralization during interactions, as active engagement may have been a channel for aggression.

\section{Relational Satisfaction}

Results regarding relational satisfaction largely met expectations, with C-couples scoring lower than ND counterparts and the IA group falling between. ${ }^{4}$ Individual-level analyses revealed the ADHD-C participants to most dissatisfied, followed by their partners (for reference, vs. ND participants, $d=1.49,1.01$, respectively). Even ADHD-IA participants reported substantially higher satisfaction than those with ADHD-C $(d=0.8)$. As Gottman and Levenson $(1992,2000)$ have noted, it is not only adaptive conflict resolution but also affective and behavioral recovery that predicts long-term relational adjustment. Failure to disengage from conflict and to regulate anger, both requiring metacognitive skills that are often impaired in individuals with ADHD-C, may engender residual negative emotional "spillover" from the conflict that further reduces satisfaction and also undermines effectiveness in other dyadic tasks (e.g., decision-making, providing emotional support; Salvatore, Kuo, Steele, Simpson \& Collins, 2011). This may be exacerbated by positive illusory bias in the ADHD-C partners, if unrealistic self-appraisals stymie adaptive change. Finally, perhaps satisfaction is less impacted by conflict behavior in IA-couples, as the affected partners typically have an avoidant (i.e., low engagement) style that would naturally minimize escalation and potentially enduring relational damage.

\section{Limitations and Future Directions}

While there was clear evidence for participants with ADHD herein meriting a diagnosis and group membership was decided via expert consensus, decisions relied on self-reports. Some question such measures' validity and reliability (e.g., Loney, Ledolter, Kramer \& Volpe, 2007), and this approach does not meet the diagnostic ideal of having multiple informants' perspectives. Still, studies show that adults' self-reports of ADHD symptoms are reliable and have acceptable agreement with those of other informants (e.g., Dias et al., 2008; Kooij et al., 2008), justifying their utility, particularly with groups such as college students who are physically separated from other qualified reporters (e.g., parents). Given the clear differences between groups across all diagnostic data and that underreporting of symptoms seems to characterize trends in the literature regarding self-report inaccuracy (see review in Kooij et al., 2008), this sample is likely representative of college students with and without ADHD. Observed differences may actually be more distinct in studies that tap more diverse ADHD populations, as college samples tend to be higher functioning than average (Mannuzza et al., 1993). Another potential direction for research in this area would be more comprehensive accounting and control for comorbidity and treatment. Variation along these lines (e.g., on medication during interaction) might impact problem-solving, communication, and satisfaction, which we were unable to explore herein.

Replication studies would also benefit from a larger sample, as in this study there was lessthan-optimal power. For analyses utilizing all three groups, power was estimated at $53-79 \%$ for medium-to-large effects, but estimates were lower for pairwise comparisons involving the IAcouples, specifically. ${ }^{5}$ As such, one certainly cannot place absolute confidence in all the nondifferences between the IA-, C-, and ND couples being "true." Accordingly, it is important that future studies achieve equality and adequacy in ADHD group cell sizes. Future studies might also use a community sample, providing wider representation of affected individuals (e.g., age range, diversity of ethnicity, and sexual preference). Regarding age, specifically, it is a common finding that hyperactivity decreases across time in individuals with ADHD (Biederman, Mick \& Faraone, 2000), and brain regions central to executive functions may still be developing in young adulthood (Diamond, 2002). Combined with research suggesting that it is inattention that causes the most dissatisfaction for non-ADHD spouses (Robin \& Payson, 2002), this suggests that conflict behaviors 
and satisfaction have the potential to change, such that IA-couples may be more disadvantaged later in life. Longitudinal designs would be most informative, as they could potentially examine how ADHD in young adulthood differentially impacts social developmental events into later adulthood (e.g., establishment of families, continuity of romantic relationship).

While no differences were found between couples with male versus female ADHD partners, results are still most generalizable to heterosexual romantic couples in which the male has ADHD (approximately 75\% of ADHD subsample). Over-selection of couples with female probands and those that have a homosexual or bisexual orientation is indicated to accurately assess relational impediments of all couples with ADHD. Similarly, it is possible that the structure of the current interactive task may have facilitated IA-probands' passivity; naturalistic data may reveal more negative behaviors. Further, prior research (Canu \& Carlson, 2003, 2007) has mainly shown relationship initiation behaviors as problematic for young men with ADHD-IA. While initial awkwardness implicitly was overcome in these dyads, it may be noticeable in newer couples.

\section{Clinical Implications}

It is well documented that couples therapy (e.g., behavioral marital therapy [BMT]) can effectively addressing both one partner's adult Axis I disorders (e.g., depression, Beach \& Whisman, 2012; substance use disorders, Powers, Vedel \& Emmelkamp, 2008); and dyadic discord (Lebow, Chambers, Christensen \& Johnson, 2012). Family therapies addressing dysfunctional relational patterns (e.g., parent-child interaction therapy) are effective at addressing ADHD and related disruptive behaviors in children (Kaslow, Broth, Smith \& Collins, 2012); in fact, family therapy for ADHD is so well established that specific standards of care have been suggested (e.g., Orr, Miller \& Polson, 2005). Unfortunately, couples therapy for ADHD lags far behind. To the authors' knowledge, only two relevant, unpublished studies exist: a case study (Yahr, 2001) and a group cognitive-behavioral therapy pilot (Wymbs \& Molina, under review), only the latter of which yielded promising results. Clearly, marriage and family therapists and other mental health practitioners can try traditional BMT and skill-building (e.g., relationship education; see review in Markman \& Rhoades, 2012) interventions with couples with an ADHD partner, which may improve the adjustment of some. However, special credence must be given to ADHD-specific issues when assessing (i.e., conceptualizing) and treating such couples. Some specific, initial suggestions for practice follow.

Analyze behavior with an ADHD lens. When disruptive behavior is present, evaluate whether it is intentional or ADHD-related. For example, imagine one partner seems uncooperative. This might reflect a withdrawing, inattentive style rather than stonewalling. In particular, this may be most indicative of a subtype of ADHD-IA characterized by sluggish cognitive tempo, which tends to present with less hyperactivity but prominent symptoms of daydreaming, confusion, and sluggishness (Hartman, Wilcutt, Rhee \& Pennington, 2004). Alternatively, one partner may often interrupt the other, causing frustration and preventing conflict resolution, but this may be more indicative of trait impulsivity than malice or disrespect. Finally, remember that common comorbidities (e.g., depression, anxiety) may also be in play, and related symptomatology could also contribute to dyadic distress. For instance, men with ADHD and comorbid depression may emit more critical and/or angry verbalizations than one with ADHD alone, which in turn could lead to caregiving burden and subsequent negativity on the part of his partner, intensifying a cycle of dissatisfaction (Benazon \& Coyne, 2000).

Incorporate ample psychoeducation. Unfortunately, the authors' experience suggests many clients with bona fide ADHD diagnoses have not learned basic information about the disorder. In addition to planned material to inform couples about the etiology and manifestation of ADHD (e.g., using select chapters of Barkley, 2010), situations like those above are "teachable moments" in which understanding and, importantly, acceptance (i.e., of abrasive behavioral tendencies) may occur, à la integrative BMT (Jacobson \& Christensen, 1998).

Use evidence-based techniques to directly address ADHD. Several cognitive-behavioral therapies for adults with ADHD have empirical support. These provide techniques that address ADHD-specific issues that have relevance to the current study and might be amenable to adaptation for couples, like learning and employing mindfulness in communication (Zilowska, 2012), 
identifying and reframing negative automatic thoughts (Safren, Perlman, Sprich \& Otto, 2005), and managing emotionally laden situations (Solanto, 2011). Additionally, pharmacotherapy has proven effective at reducing symptoms of ADHD (Dodson, 2005); especially given the findings herein, in cases where severe hyperactivity-impulsivity is affecting a couple's adjustment, referral to psychiatric consultation is warranted.

\section{CONCLUSION}

This is the first published study to investigate in vivo conflict behavior of couples with ADHD partners and documents that the combined type of ADHD raises the risk for ineffective communication and relational dissatisfaction. This contrasts with the relatively functional interaction of couples with a partner with the predominantly inattentive type, which were largely comparable to ND couples. The findings are particularly concerning given the elevation of all Gottman's FourHorsemen-of-the-Apocalypse behaviors in C-couples, which is predictive of relational dissolution (Gottman, 1996; Gottman \& Driver, 2005; Gottman \& Levenson, 2000). Without empirically supported couples therapies for ADHD, therapists are encouraged to evaluate disruptive behavior on the part of affected partners with ADHD in mind, use psychoeducation to encourage awareness and forgiveness, and to incorporate interventions that are effective for individuals with ADHD into their couples practice.

\section{REFERENCES}

American Psychiatric Association (2000). Diagnostic and statistical manual of mental disorders (4th ed. text revision). Washington, DC: American Psychiatric Association.

Barkley, R. A. (2006). Attention deficit hyperactivity disorder: A handbook for diagnosis and treatment. New York: Guilford.

Barkley, R. A. (2010). Taking charge of adult ADHD. New York: Guilford.

Barkley, R. A., Knouse, L. E., \& Murphy, K. R. (2011). Correspondence and disparity in the self- and other ratings of current and childhood ADHD symptoms and impairment in adults with ADHD. Psychological Assessment, 23,437-444.doi:10.1037/a0022172.

Barkley, R. A., \& Murphy, K. R. (2006). Attention-deficit/hyperactivity disorder: A clinical workbook. New York: Guilford.

Beach, S. R. H., \& Whisman, M. A. (2012). Affective disorders. Journal of Marital and Family Therapy, 38, 201-219. doi:10.1111/j.1752-0606.2011.00243.x.

Benazon, N. R., \& Coyne, J. C. (2000). Living with a depressed spouse. Journal of Family Psychology, 14,71-79. doi:10.1037//0893-3200.14.1.71.

Biederman, J., Faraone, S. V., Spencer, T. I., Mick, E., Monuteaux, M. C., \& Aleardi, M. (2006). Functional impairments in adults with self-reports of diagnosed ADHD: A controlled study of 1,001 adults in the community. Journal of Clinical Psychiatry, 67, 524-540. doi:10.4088/JCP.v67n0403.

Biederman, J., Mick, E., \& Faraone, S. V. (2000). Age-dependent decline of symptoms of attention deficit hyperactivity disorder: Impact of remission definition and subtype. American Journal of Psychiatry, 157, 816-818.doi:10. 1176/appi.ajp. 157.5.816.

Buehlman, K. T., Gottman, J. M., \& Katz, L. F. (1992). How a couple views their past predicts their future: Predicting divorce from an oral history interview. Journal of Family Psychology, 5, 295-318.

Canu, W. H., \& Carlson, C. L. (2003). Differences in heterosocial behavior and outcomes of ADHD symptomatic subtypes in a college sample. Journal of Attention Disorders, 6, 123-133. doi:10.1177/108705470300600304.

Canu, W. H., \& Carlson, C. L. (2007). Rejection sensitivity and social outcomes of young men with ADHD. Journal of Attention Disorders, 10, 261-275. doi:10.1177/1087054706288106.

Carlson, C. L., Booth, J. E., Shin, M., \& Canu, W.H. (2002). Parent-, teacher-, and self-rated motivational styles in ADHD subtypes. Journal of Learning Disabilities, 35, 104-113.

Conners, C. K., Erhardt, D., \& Sparrow, M. A. (1999). Conners adult ADHD rating scales (CAARS). New York: Multihealth Systems.

Diamond, A. (2002). Normal development of prefrontal cortex from birth to young adulthood: Cognitive functions, anatomy, and biochemistry. In D. T. Stuss \& R. T. Knight (Eds.), Principles of frontal lobe function (pp. 466-503). New York: Oxford. doi:10.1093/acprof:oso/9780195134971.003.0029.

Dias, G., Mattos, P., Coutinho, G., Segenreich, D., Saboya, E., \& Ayrão, V. (2008). Agreement rates between parent and self-report on past ADHD symptoms in an adult clinical sample. Journal of Attention Disorders, 12, 70-75. doi:10.1177/1087054707311221. 
Dodson, W. W. (2005). Pharmacotherapy of adult ADHD. Journal of Clinical Psychology, 61, 589-606. doi:10.1002/ jclp. 20122.

Downey,G., \& Feldman, S. I.(1996). Implication of rejection sensitivity forintimaterelationships. JournalofPersonality and Social Psychology, 70, 1327-1343.

Eakin, L., Minde, K., Hechtman, L., Ochs, E., Krane, E., Bouffard, R., etal. (2004). The marital and family functioning of adults with ADHD and their spouses. Journal of Attention Disorders, 8, 1-10. doi:10.1177/ 108705470400800101.

Eisenberg, D., Schneider, H. (2007). Perceptions of academic skills of children diagnosed with ADHD. Journal of Attention Disorders, 10, 390-397. doi: 10.1177/1087054706292105.

Evangelista, N. M., Owens, I. S., Golden, C. M., \& Pelham, W. E., Ir. (2008). The positive illusory bias: Do inflated self-perceptions in children with ADHD generalize to perceptions of others? Journal of Abnormal Child Psychology, 36, 779-791. doi:10.1007/s10802-007-9210-8.

Fedele, D. A., Hartung, C. M., Canu, W.H., \&Wilkowski, B. M.(2010). Potential symptoms of ADHD for emerging adults. JournalofPsychopathology and Behavioral Assessment,32,385-396.doi:10.1007/s10862-009-9173-x.

Flory, K., Molina, B., Pelham, W.E., Gnagy, E., \& Smith, B. (2006). Childhood ADHD predicts risky sexual behavior in young adulthood. Journal of Clinical Child and Adolescent Psychology, 35, 571-577.

Friendly, M. (2012). Power analysis for ANOVA designs [Statistical calculator]. Retrieved January 14, 2013, from http://euclid.psych.yorku.ca/SCS/Online/power/.

Gaub, M., \& Carlson, C. L. (1997). Behavioral characteristics of DSM-IV ADHD subtypes in a school-based population. Journal of Abnormal Child Psychology, 25, 103-111. doi:10.1023/A:1025775311259.

Gottman,J. M.(1996). What predicts divorce? The measures. Mahwah, NJ: Lawrence Erlbaum.

Gottman, I. M., \& Driver, I. L. (2005). Dysfunctional martial conflict and everyday marital interaction. Journal of Divorce \& Remarriage, 43,63-77. doi:10.1300/J087v43n03 04.

Gottman, J. M., \& Levenson, R. W. (1992). Marital process predictive of later dissolution: Behavior, physiology, and health.Journal of Personality and Social Psychology, 63, 221-233. doi:10.1037/0022-3514.63.2.221.

Gottman, I. M., \& Levenson, R. W. (2000). The timing of divorce: Predicting when a couple will divorce over a 14-year period. Journal of Marriage and the Family, 60,5-22.

Graetz, B. W., Sawyer, M. G., Hazell, P. L., Franz, C. P., Arney, F., \& Baghurst, P. (2001). Validity of DSM-IV ADHD subtypes in a nationally representative sample of Australian children and adolescents. Journal of the American Academy of Child and Adolescent Psychiatry, 40, 1410-1417. doi:10.1097/ 00004583-200112000-00011.

Hartman, C. A., Wilcutt, E. G., Rhee, S. H., \& Pennington, B. F. (2004). The relation between sluggish cognitive tempo and DSM-IV ADHD. Journal of Abnormal Child Psychology, 32, 491-503. doi:10.1023/B:JACP. $\underline{0000037779.85211 .29 .}$

Hendrick, S. (1988). A generic measure of relationship satisfaction. Journal of Marriage and the Family, 50,93-98. doi:10.2307/352430.

Henker, B., \& Whalen, C. K. (1999). The child with Attention-Deficit/Hyperactivity Disorder in school and peer settings. In H. C. Quay \& A. E. Hogan (Eds.), Handbook of disruptive behavior disorders (pp. 157-178). New York: Kluwer Academic/Plenum.

Hinshaw, S. P., \& Melnick, S. M. (1995). Peer relationships in boys with attention-deficit/hyperactivity disorder with and without comorbid aggression. Development and Psychopathology, 7, 627-647.

Hoza, B., Mrug, S., Gerdes, A. C., Hinshaw, S. P., Bukowski, W. M., Gold, I. A., et al (2005). What aspects of peer relationships are impaired in children with Attention-Deficit/Hyperactivity Disorder? Journal of Consulting and Clinical Psychology, 73, 411-423. doi:10.1037/0022-006X.73.3.411.

Jacobson, N.S., \& Christensen, A. (1998). Acceptance and change in couple therapy: A therapist's guide to transforming relationships. New York: Norton.

Johnston, C., \& Freeman, W. (1997). Attributions for child behavior in parents of children without behavior problems and children with attention deficit-hyperactivity disorder. Journal of Consulting and Clinical Psychology, 65, 636-645.

Kaslow, N. J., Broth, M. R., Smith, C. O., \& Collins, M. H. (2012). Family-based interventions for child and adolescent disorders. Journal of Marital andFamily Therapy, 38,82-100. doi:10.111/j.1752-0606.2011.00257.x.

Kessler, R. C., Adler, L., Barkley, R. O., Biederman, I., Connors, C. K., \& Demler, O. (2006). The prevalence and correlates of ADHD in the United States: Results from the National Comorbidity Survey Replication (NCS-R). American Journal of Psychiatry, 163, 716-723. doi:0066-4219/02/0218-0113.

Knouse, L. E., Bagwell, C. L., Barkley, R. A., \& Murphy, K. R. (2005). Accuracy of self-evaluation in adults with ADHD: Evidence from a driving study. Journal of Attention Disorders, 8, 221-234. doi:10.1177/ 1087054705280159.

Knouse, L. E., Mitchell, J. T., Brown, L. H., Silvia, P. J., Kane, M. J., Myin-Germeys, I., et al. (2008). The expression of adult ADHD symptoms in daily life. Journal of Attention Disorders, 11, 652-663. doi:10.1177/ 1087054707299411. 
Kooij, S. J. J., Boonstra, M., Swinkels, S. H. N., Bekker, E. M., de Noord, I., \& Buitelaar, J. K. (2008). Reliability, validity, and utility of instruments for self-report and informant report concerning symptoms of ADHD in adult patients. Journal of Attention Disorders, 11, 445-458. doi:10.1177/1087054707299367.

Lebow, J. L., Chambers, A. L., Christensen, A., \& Johnson, S. M. (2012). Research on the treatment of couple distress.JournalofMarital and Family Therapy,38,145-168.doi:10.1111/j.1752-0606.2011.00249.x.

Loney, I., Ledolter, I., Kramer, I. R., \& Volpe, R. I. (2007). Retrospective ratings of ADHD symptoms made at young adulthood by clinic-referred boys with ADHD-related problems, their brothers without ADHD, and control participants. Psychological Assessment, 19, 269-280. doi:10.1037/1040-3590.19.3.269.

Mannuzza, S., Klein, R. G., Bessler, A., Malloy, P., \& LaPadula, M. (1993). Adult outcome of hyperactive boys: Educational achievement, occupational rank, and psychiatric status. Archives of General Psychiatry, 50, 565-576.

Markman, H. I., \& Rhoades, G. K. (2012). Relationship education research: Current status and future directions. Journal of Marital and Family Therapy, 38, 169-200. doi:10.1111/j.1752-0606.2011.00247.x.

Melby, I. N., Ge, X., Conger, R. D., \& Warner, T. D. (1995). The importance of task in evaluating positive marital interactions. Journal of Marriage and the Family, 57, 981-994.

Minde, K., Eakin, L., Hechtman, L., Ochs, E., Bouffard, R., Greenfield, B., et al. (2003). The psychosocial functioning of children and spouses of adults with ADHD. Journal of Child Psychology and Psychiatry, 44, 637-646. doi:10.1111/1469-7610.00150.

Mrug, S., Hoza, B., Gerdes, A. C., Hinshaw, S., Arnold, L. E., Hechtman, L., et al. (2009). Discriminating between children with ADHD and classmates using peer variables. Journal of Attention Disorders, 12, 372-380. doi:10. $1177 / 1087054708314602$.

Murphy, K., \& Barkley, R. A. (1996). Attention-deficit/hyperactivity disorder adults: Comorbidities and adaptive impairments. Comprehensive Psychiatry, 37, 393-401.

Norvilitis, J. M., Sun, L., \&Zhang, J. (2010). ADHD symptomatology and adjustment to college in China and the United States. Journal of Learning Disabilities, 43,86-94. doi:10.1177/0022219409345012.

Orr, I. M., Miller, R. B., \& Polson, D. M. (2005). Toward a standard of care for child ADHD: Implications for marriage and family therapists. Journal of Marital and Family Therapy, 31, 191-205. doi:10.1111/j.1752-0606.2005. tb01563.x.

Powers, M. B., Vedel, E., \& Emmelkamp, P. M. G. (2008). Behavioral couples therapy (BCT) for alcohol and drug use disorders: A meta-analysis. Clinical Psychology Review, 28, 952-962. doi:10.1016/i.cpr.2008.02.002.

Robin, A. L., \& Payson, E. (2002). Theimpact of ADHD on marriage. The ADHD Report, 10,9-11.

R€ sler, M., Retz, W., Thome, J., Schneider, M., Stieglitz, R.-D., \& Falkai, P. (2006). Psychopathological rating scales for diagnostic use in adults with attention-deficit/hyperactivity disorder (ADHD). European Archives of Psychiatry and Clinical Neuroscience, 256(Suppl 1), 3-11. doi:10.1007/s00406-006-1001-7.

Safren, S. A., Perlman, C. A., Sprich, S., \& Otto, M. W.(2005). Masteringyour adult ADHD: A cognitive-behavioral treatment program therapist guide. New York: Oxford.

Salvatore, I. E., Kuo, S., Steele, R. D., Simpson, I. A., \& Collins, W. (2011). Recovering from conflict in romantic relationships: A developmental perspective. Psychological Science, 22, 376-383. doi:10.1177/0956797610397055.

Schneewind, K.A., \& Gerhard,A.-K.(2002). Relationship personality, conflict resolution, and marital satisfaction in the first 5 yearsof marriage. Family Relations, 51,63-71. doi:10.1111/i.1741-3729.2002.00063.x.

Solanto, M. V. (2011). Cognitive-behavioral therapy for adult ADHD: Targeting executive dysfunction. New York: Guilford.

Theriault, S. W., \& Holmberg, D. (2001). Impulsive, but violent? Are components of the attention deficit-hyperactivity syndrome associated with aggression in relationships? Violence Against Women, 7, 1464-1489. doi:10.1177/ 10778010122183946.

Ward, M. F., Wender, P. H., \& Reimherr, F. W. (1993). The Wender Utah Rating Scale: An aid in the retrospective diagnosis of childhood attention deficit hyperactivity disorder. American Journal of Psychiatry, 150, 885-890.

Weiss, M., Hechtman, L. T., \& Weiss, G. (1999). ADHD in adulthood: A guide to current theory, diagnosis, and treatment. Baltimore, MD: Johns Hopkins University Press.

Wilens, T. E., Biederman, J., \& Spencer, T. J. (2002). Attention-deficit/hyperactivity disorder across the lifespan. Annual Review of Medicine, 53, 113-131.

Wymbs, B. T., \& Molina, B. S. G. (under review). Treating emerging adults with ADHD in the context of Romantic Relationships: Preliminary results from an open pilot trial of a CBT couples group intervention. Manuscript submitted for publication.

Wymbs, B., Molina, B., Pelham,W., Cheong,J., Gnagy, E., Belendiuk, K., etal.(2012). Riskofintimatepartnerviolence among young adult males with childhood ADHD. Journal of Attention Disorders, 16, 373-383. doi:10. $1177 / 1087054710389987$.

Yahr, G. W. (2001). Attention deficit hyperactivity disorder and couples treatment: An intervention program for couples when one of the partners has been diagnosed with attention deficit hyperactivity disorder. Dissertation Abstracts International: Section B: The Sciences and Engineering, 62(8-B), 3820. 
Zilowska, L. (2012). The mindfulness prescription for adult ADHD: An 8-step program for strengthening attention, managing emotions, and achieving your goals. Boston, MA: Trumpeter Books.

\section{NOTES}

${ }^{1}$ With the noted exception of both partners $>3 S D$ above the mean, age was not constrained; however, the vast majority (90.5\%) of participants were $<25$ years old, as might be expected in a college sample. One participant was $<18$ years and $>30$ years old, each.

${ }^{2} \mathrm{~A}$ proband is a person receiving medical (or psychological) services; in this article, it will be used in reference to participants who have an ADHD diagnosis.

${ }^{3}$ Omnibus exploratory analyses tested whether dependent variable data varied with biological sex of ADHD partner. These were $n s$ ( $p s>.26$ ); further exploration of this issue was curtailed.

${ }^{4}$ IA-ND comparison was not statistically significant, and the magnitude of difference $(\sim$ medium effect, $d=0.47$ ) and direction of scores partially support the satisfaction hypothesis.

${ }^{5}$ Three-group ANOVA, assuming $n=20$, effect sizes of 0.75 and 1.0. Pairwise example: IA- versus ND couples on RCISS negative composite, cell size set at 14 : power $=38-62 \%$ (Friendly, 2012). 